Rowan University

Rowan Digital Works

Stratford Campus Research Day

22nd Annual Research Day

May 3rd, 8:00 AM

\title{
A Case of Signet Ring Cell Colon Carcinoma Initially Presenting As Acute Diverticulitis
}

\author{
Justin DeRosa DO \\ Rowan University SOM \\ Jonathan Foster DO \\ Rowan University SOM \\ Drew Chiesa DO \\ Rowan University SOM \\ Darshan Roy MD \\ Rowan University SOM
}

Follow this and additional works at: https://rdw.rowan.edu/stratford_research_day

Part of the Analytical, Diagnostic and Therapeutic Techniques and Equipment Commons, Digestive System Diseases Commons, and the Neoplasms Commons

Let us know how access to this document benefits you - share your thoughts on our feedback form.

DeRosa, Justin DO; Foster, Jonathan DO; Chiesa, Drew DO; and Roy, Darshan MD, "A Case of Signet Ring Cell Colon Carcinoma Initially Presenting As Acute Diverticulitis" (2018). Stratford Campus Research Day. 8.

https://rdw.rowan.edu/stratford_research_day/2018/may3/8

This Poster is brought to you for free and open access by the Conferences, Events, and Symposia at Rowan Digital Works. It has been accepted for inclusion in Stratford Campus Research Day by an authorized administrator of Rowan Digital Works. 


\section{Learning Objectives}

Highlight guidelines and importance on colon cancer screening Educate on follow-up colonoscopy following diverticulitis treatment Enlighten clinicians on signet ring cell cancer

Introduction

Signet ring cell cancer is a very rare and deadly type of colon malignancy

Case profiles a unique circumstance where a patient with a final

diagnosis of signet ring cell carcinoma originally presented with acute diverticulitis

\section{Signet Ring Cell Histology}

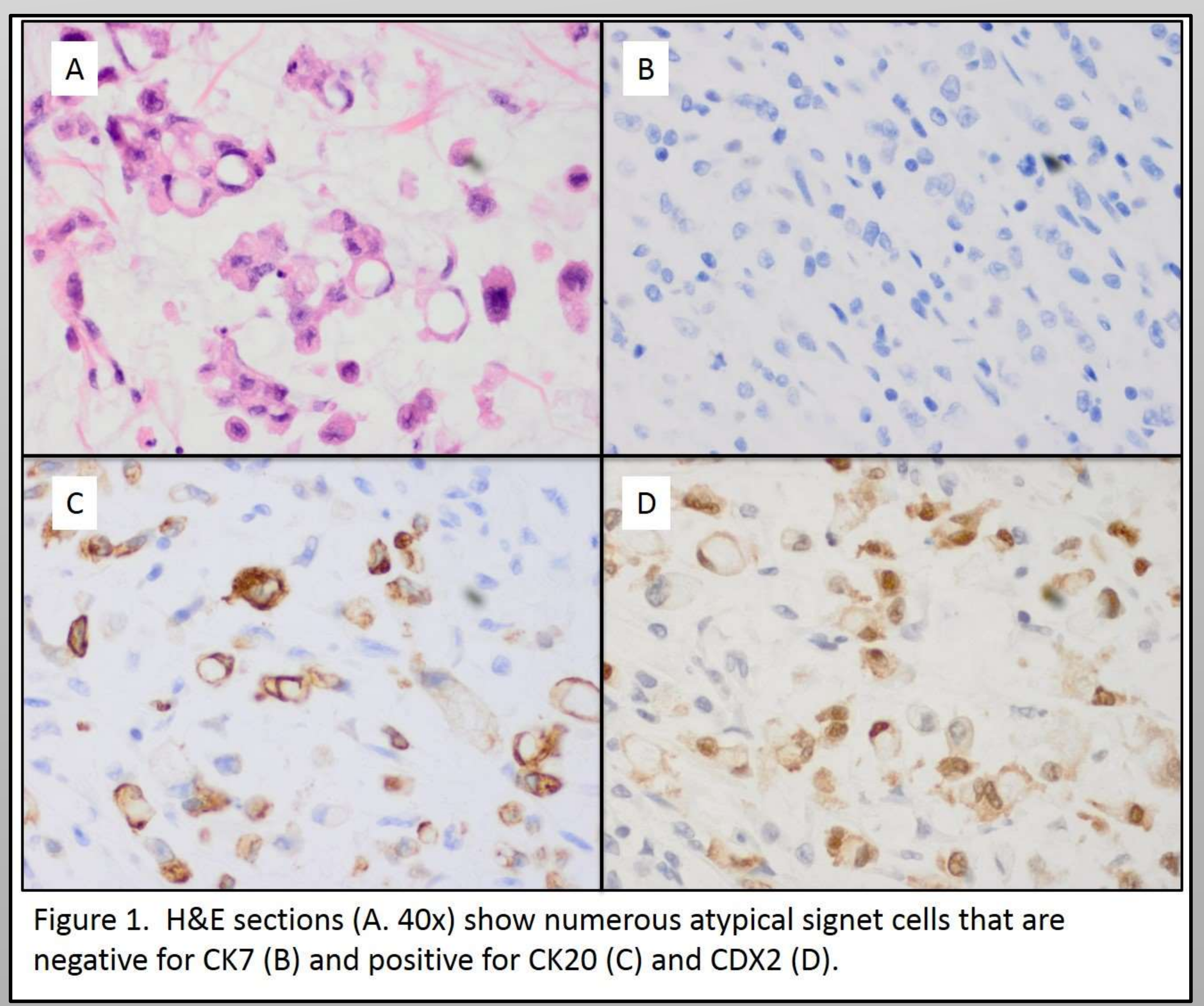

Patient Case

HPI

- 53 y.o. Caucasian female with sharp LLQ abdominal pain

ROS

- No fevers, diarrhea, rectal bleeding, emesis, melena $\mathrm{PMH}$

- Diabetes, Hypertension

PSH

- No prior colonoscopies or endoscopies Social $\mathrm{Hx}$

No recent travel or sick contacts

Family $\mathrm{Hx}$

- No gastroenterological disorders or cancers

Labs

- WBC- 12.6

Imaging

- CT scan A/P- moderate diverticulosis with mural thickening of the proximal sigmoid colon with

adjacent edema and free pelvic fluid

- $4.5 \mathrm{~cm}$ abscess inferior to the proximal sigmoid colon Hospital course

- Placed on piperacillin/tazobactam for diverticulitis

- Interventional Radiology for drainage of abscess Post Hospital Course

- 6 week follow up colonoscopy showing obstructing mass lesion $20-25 \mathrm{~cm}$ from the anal verge

Sigmoidectomy with primary anastomosis

- Pathology - high grade, poorly differentiated signet-ring cell carcinoma with metastatic carcinoma in 11 out of the 12 surrounding lymph nodes.

Discussion

- Signet Ring Cell Facts

- Signet ring cell cancer present in $<1 \%$ of all colon cancers ${ }^{1}$

- First known incidence of signet ring cell carcinoma of the colon was reported in $1951^{2}$

- Signet ring cell cancer is predominately located in the stomach $(99 \%)$ when found in the $\mathrm{Gl}$ tract $^{3}$

- Named for physical appearance of dominant cell type

- Cells must comprise $>50 \%$ of total amount of tumor cells ${ }^{2}$

- More likely to present at later stage than adenocarcinoma ${ }^{4}$

- More common in patients with IBD and history or radiation exposure ${ }^{2}$

- High frequency of BRAF mutations 2

- Common presentation involves rectal bleeding, SBO, abdominal pain, hematochezia, abdominal mass, changes in bowel habits ${ }^{2}$

Colorectal Cancer Screening Guidelines Involving Colonoscopy in patient with no risk factors (ACG guidelines)

- Begin at age 50 with repeat every 10 years

- Begin at age 45 in African Americans

Guidelines for colonoscopy following diverticulitis

- Screening should take place 6 to 8 weeks following resolution of diverticulitis

\section{Conclusion}

Signet ring cell cancer is a very rare from of colon malignancy Case highlights the importance of patients obtaining follow-up colonoscopy following a diagnosis of diverticulitis and the continued need for routine screening colonoscopies to detect and prevent the occurrence of colon cancer.

\section{References}

